\title{
Erratum to: Osteosarcoma follow-up: chest X-ray or computed tomography?
}

Anna Paioli ${ }^{*}{ }^{*}$, Michele Rocca ${ }^{2}$, Luca Cevolani ${ }^{3}$, Eugenio Rimondi ${ }^{4}$, Daniel Vanel ${ }^{4}$, Emanuela Palmerini ${ }^{1}$, Marilena Cesari ${ }^{1}$, Alessandra Longhi ${ }^{1}$, Massimo Eraldo Abate ${ }^{1}$, Emanuela Marchesi ${ }^{1}$, Piero Picci ${ }^{5}$ and Stefano Ferrari ${ }^{1}$

\section{Erratum to: Clin Sarcoma Res (2017) 7:3 DOI 10.1186/s13569-017-0067-5}

It was noticed that there was an error in the author list, upon publication of the original article [1]. The ninth author should be listed as Massimo Eraldo Abate.

\begin{abstract}
Author details
${ }^{1}$ Chemotherapy Unit, Istituto Ortopedico Rizzoli, via Pupilli, 1, 40136 Bologna, Italy. ${ }^{2}$ General Surgery Unit, Istituto Ortopedico Rizzoli, via Pupilli, 1 , 40136 Bologna, Italy. ${ }^{3}$ Department of Orthopaedic Oncology, Istituto Ortopedico Rizzoli, via Pupilli, 1, 40136 Bologna, Italy. ${ }^{4}$ Diagnostic and Interventional Radiology, Istituto Ortopedico Rizzoli, via Pupilli, 1, 40136 Bologna, Italy.

${ }^{5}$ Department of Pathology, Istituto Ortopedico Rizzoli, via di Barbiano, 1/10, 40136 Bologna, Italy.
\end{abstract}

The online version of the original article can be found under doi:10.1186/s13569-017-0067-5.

\section{Publisher's Note}

Springer Nature remains neutral with regard to jurisdictional claims in published maps and institutional affiliations.

Received: 6 April 2017 Accepted: 12 April 2017

Published online: 03 May 2017

\section{Reference}

1. Paioli A, Rocca M, Cevolani L, Rimondi E, Vanel D, Palmerini E, Cesari M, Longhi A, Abate ME, Marchesi E, Picci P, Ferrari S. Osteosarcoma followup: chest X-ray or computed tomography? Clin Sarcoma Res. 2017;7:3. doi:10.1186/s13569-017-0067-5.

\footnotetext{
*Correspondence: anna.paioli@ior.it

${ }^{1}$ Chemotherapy Unit, Istituto Ortopedico Rizzoli, via Pupilli, 1,

40136 Bologna, Italy

Full list of author information is available at the end of the article
} 